\title{
Leibniz's Optics and Contingency in Nature
}

\section{Citation}

McDonough, Jeffrey K. 2010. Leibniz's Optics and Contingency in Nature. Perspectives on Science 18(4): 432-455.

\section{Published Version}

doi:10.1162/POSC_a_00017

\section{Permanent link}

http://nrs.harvard.edu/urn-3:HUL.InstRepos:5128571

\section{Terms of Use}

This article was downloaded from Harvard University's DASH repository, and is made available under the terms and conditions applicable to Open Access Policy Articles, as set forth at http:// nrs.harvard.edu/urn-3:HUL.InstRepos:dash.current.terms-of-use\#OAP

\section{Share Your Story}

The Harvard community has made this article openly available.

Please share how this access benefits you. Submit a story.

Accessibility 
Leibniz’s Optics and Contingency in Nature

Jeffrey K. McDonough

Department of Philosophy

Harvard University 


\begin{abstract}
In the late 1670's to early 1680's, Leibniz came to hold that the laws of nature are paradigmatically contingent, that they provide the basis for a new argument from design, and that they presuppose the existence of active, goal-directed powers reminiscent of Aristotelian entelechies. In this essay, I argue that the standard view according to which Leibniz forges these signature theses in the domain of physics and opportunistically carries them over to the domain of optics gets things essentially the wrong way around. The crucial nexus of views at the heart of Leibniz's mature philosophical understanding of the laws of nature has its most intelligible roots in his optical derivations, which appear to have paved the way - both historically and conceptually - for the philosophical significance he assigns to his discoveries in the domain of physics. Optics the horse, as it were, physics the cart.
\end{abstract}




\section{Introduction}

Leibniz’s mature philosophical understanding of the laws of nature emerges rather suddenly in the late 1670's to early 1680's and is signaled by his embrace of three central theses. ${ }^{1}$ The first, what I'll call the thesis of Contingency, suggests that the laws of nature are not only contingent, but, in some sense, paradigmatically contingent; they are supposed to provide insight into the very nature of contingency as Leibniz comes to understand it. The second, what I'll call the thesis of Providence, suggests that the laws of nature provide a basis for a new argument from design by showing how reflection on God's ends can be positively useful in the practice of natural philosophy. The third, what I'll call thesis of Entelechies, insists that the actual laws of nature must be grounded in goal-directed, teleological natures, which vindicate, in at least some measure, the Aristotelian-Scholastic tradition’s postulation of immanent teleology.

In trying to understand his embrace of these three theses, Leibniz's commentators have typically looked to his work in dynamics, and in particular to his famous "discovery" of the law of the conservation of vis viva and his concomitant rejection of Descartes's law of the conservation of quantity of motion. ${ }^{2}$ And not without reason. For

\footnotetext{
${ }^{1}$ Margaret Wilson previously drew attention to these three theses in her seminal paper, “Leibniz’s Dynamics and Contingency in Nature,” (Wilson, 1976). The title of the present paper is, of course, an allusion to her title.

2 "Discovery" in scare quotes because the technical result that Leibniz seizes upon, and does so much to develop philosophically, was already available in the work of his
} 
Leibniz clearly came to see his work on the laws of motion and impact as lending important support to his mature philosophical understanding of the laws of nature. Thus, for example, in a passage indicative of the thesis of Contingency, he tells us, "this great example of the laws of motion shows us with the utmost clarity how much difference there is between these three cases ... first, an absolute necessity, ... second $a$ [merely] moral necessity ... and finally third something absolutely arbitrary” (T 349, see also G III 645). ${ }^{3}$ In a passage that recalls the thesis of Providence, he relates, "since we have

predecessors, and in particular in the work of Christiaan Huygens with whom Leibniz studied while in Paris (1672-1676). For helpful discussion of influences on Leibniz's work on the laws of physics, see especially, chapter 4 of Gueroult (1967), chapters 4-6 of Westfall (1971), as well as Westfall (1984) and Bos (1978). See also the references in footnote 4 below.

${ }^{3}$ I will use the following abbreviations for Leibniz's works (full citations available in the reference section): A = German Academy of Sciences (ed.) Gottfried Wilhelm Leibniz: Sämtliche Schriften und Briefe, (Leibniz, 1923-), reference is to series, volume and page. AG $=$ R. Ariew and D. Garber (eds. and trans.) G. W. Leibniz: Philosophical Essays, (Leibniz, 1989), reference is to series, volume and page. DM = G. W. Leibniz, "Discourse on Metaphysics," in G IV 427-63, reference is to section number. FW = R. Franks and R. Woolhouse (eds.) G. W. Leibniz: Philosophical Texts, (Leibniz, 1988). G = C. I. Gerhardt (ed.) Die Philosophischen Schriften von Gottfried Wilhelm Leibniz, 7 volumes (Leibniz, 1875-1890), reference is to volume and page. Gerland = Ernst Gerland, Leibnizens Nachgelassene Schriften Physikalischen, Mechanischen und Technischen Inhalts (Leibniz, 1906), reference is to section number. GM = C. I. 
always recognized God's wisdom in the detail of the mechanical structure of some particular bodies, it must also be displayed in the general economy of the world and in the constitution of the laws of nature ... one can observe the counsels of this wisdom in the laws of motion in general” (DM 21, see also T 345). Finally, in a passage supportive of the thesis of Entelechies, Leibniz tells us, "Certain things take place in a body which cannot be explained from the necessity of matter alone. Such are the laws of motion, which depend upon the metaphysical principle of the equality of cause and effect. Therefore we must deal here with the soul and show that all things are animated” (A VI.iv.1988/L 278, see also DM 18, 21, 23).

Without wishing to deny that Leibniz's work in dynamics came to play an important role in his thinking about the philosophical foundations of the laws of nature, in the three sections that follow I would like to draw attention to an alternative source of

Gerhardt (ed.) G. W. Leibniz: Mathematische Schriften, 7 volumes (Leibniz, 1849-63), reference is to volume and page. L = L. E. Loemker, (ed. and trans.) Gottfried Wilhelm Leibniz: Philosophical Papers and Letters, $2^{\text {nd }}$ Edition, (Leibniz, 1969). LC $=$ Richard Arthur (ed. and trans.) The Labyrinth of the Continuum, Writings on the Continuum Problem, 1672-1686, (Leibniz, 2001). LH = Eduard Bodemann, Die LeibnizHandschriften der Königlichen öffentlichen Bibliothek zu Hannover (Leibniz, 1889) reference is to folio number and page. NE = G. W. Leibniz, New Essays on Human Understanding, in A.VI.6; reference is to book, chapter, section. NI = G. W. Leibniz, “On Nature Itself,” in G IV 504-16; SD = G. W. Leibniz, "A Specimen of Dynamics,” in GM 6: 235-54, reference is to part and paragraph. T = G. W. Leibniz, Theodicy in G VI; English translation by E. M. Huggard (Leibniz, 1985), reference is to section number. 
his commitment to the theses of Contingency, Providence, and Entelechies. Each of the three following sections accordingly takes up one of Leibniz's signature theses and argues that it is best understood as arising out of his work in geometrical optics rather than out of his studies in dynamics. The intended moral of the three sections taken together is that, while it has been tempting to suppose that Leibniz forges the central theses of his mature understanding of the laws of nature in the domain of physics and opportunistically carries them over to the domain of optics, such a story appears to get things essentially the wrong way around. The crucial nexus of views at the heart of Leibniz's mature philosophical understanding of the laws of nature has its most intelligible roots in his optical derivations, which appear to have paved the way - both historically and conceptually - for the philosophical significance he assigns to his discoveries in the domain of physics. Optics the horse, as it were, physics the cart.

\section{Contingency}

The most promising strategy for directly linking Leibniz's embrace of Contingency with his work in dynamics centers on his derivation of the conservation of vis viva as presented in his Brief Demonstration of 1686 and elsewhere (GM VI 117-119/L 296-302; GM VI 234-254/AG 117-138; GM VI 287-92/AG 105-111). ${ }^{4}$ In those derivations,

\footnotetext{
${ }^{4}$ For discussion of Leibniz's derivations of the conservation of vis viva as well as the controversy to which it helped give birth, see especially, Laudan (1968), Gale (1973), Iltis (1974) and (1979), Garber (1995), and Smith (2006). See also the references in footnote 2 above.
} 
Leibniz argues that the conservation of vis viva follows from - among other things - the principle of the equality of cause and effect, that is, the principle that "the same sum of motive force should be conserved in nature and not be diminished - since we never see force lost by one body without being transferred to another” (GM VI 117/L 296). Assuming that the equality principle holds contingently, one might imagine that since the conservation of vis viva can be, or even must be, grounded in, or derivable from, a contingent feature of the world, it must itself be a contingent feature of the world. ${ }^{5}$ And, indeed, Leibniz appears to endorse this line of thought in several texts, including a passage from the Theodicy in which he emphasizes, "I discovered at the same time that the laws of motion actually existing in Nature, and confirmed by experiments, are not in reality absolutely demonstrable, as a geometrical proposition would be . . . They do not spring entirely from the principle of necessity, but rather from the principle of perfection and order ... I can demonstrate these laws in diverse ways, but must always assume something that is not of an absolutely geometrical necessity” (T 345, see also DM 21). While the suggestion that the laws of nature must be contingent because they follow from contingent principles clearly plays a role in Leibniz's mature thinking about the laws of nature, as an account of how he came to embrace Contingency, it meets with two formidable difficulties. ${ }^{6}$

\footnotetext{
${ }^{5}$ See especially of Garber (1995, pp. 319-20; forthcoming, ch. 4). See also in Wilson (1976, pp. 428-431), Posner (1984), Okruhlik (1995).

${ }^{6}$ Setting aside, of course, concerns over the argument's validity: since nothing precludes the derivation of a necessary truth from contingent premises, it is not clear why it should not be possible to derive even a necessary law from a contingent principle.
} 
The first is an historical worry: in his early studies of the laws of motion and impact, Leibniz insists, and repeatedly attempts to prove, that the equality of cause and effect holds of absolute necessity. ${ }^{7}$ Indeed, Daniel Garber has recently argued that we do not find clear textual evidence of Leibniz's commitment to the contingency of the equality principle before December 1679 (A2.1.495/L 272). ${ }^{8}$ In that case, however, appealing to the equality principle in order to explain Leibniz's embrace of Contingency would seem to merely push things back a step. For even granting that his understanding of the modal status of the laws of nature was influenced by his understanding of the modal status of the equality principle, we should still like to know, what might have led Leibniz, sometime around the late 1670's to early 1680's, to change his mind about the modal status of the equality principle itself? ${ }^{9}$

The second difficulty is one of conceptual fit: although Leibniz insists that the laws of nature provide a model of his mature view of contingency, neither the

\footnotetext{
${ }^{7}$ See, especially, Leibniz (1675). See also, A VI.iv.1963-4.

${ }^{8}$ Garber (forthcoming, ch. 6).

${ }^{9}$ Responding to essentially this challenge, Daniel Garber (forthcoming, ch. 6) has suggested that Leibniz's conversion might have been spurred by his frustration in proving the equality principle and his growing awareness of the threat posed by Spinoza's rejection of final causes. As Garber himself notes, however, such an account faces an important objection in that, already early in his career, Leibniz seems to have distinguished quite clearly between teleological providence on the one hand, and contingency on the other, arguing that the creation of the world might be both providential and necessary (see, for example, A VI.iii.364; A VI.iii.370).
} 
conservation of vis viva nor the equality principle seem like especially compelling or illuminating examples of Leibnizian contingency in nature. The conservation of vis viva is, of course, a striking and elegant law in its own right, and even plausibly contingent. But much the same could be said of almost any candidate law of nature. Indeed, it is hard to see why the conservation of vis viva, per se, should be thought to be a better example of contingency in nature than, say, Descartes's conservation of the quantity of motion. The equality principle is likewise admittedly striking and elegant in its own right. But it, in particular, seems like an unlikely original paradigm of contingency for Leibniz given his early attempts to establish that it is essentially an analytic truth. Thus, although both the conservation of vis viva and the equality principle might be interpreted in a way that is consistent with the thesis of Contingency, neither seems to be an especially suggestive example of Leibniz's mature understanding of contingency in nature.

Leibniz's work in geometrical optics promises solutions to both of these difficulties, and in doing so points the way towards a more sympathetic account of his embrace of the thesis of Contingency.

The foundations for a better model of Leibniz's mature understanding of contingency are clearly on display in his relatively late and well-known Tentamen Anagogicum of 1696 (G VII 270-9/L 485). In that piece he offers a pair of sophisticated derivations of the two central laws of geometrical optics, the law of reflection and the law of refraction. ${ }^{10}$ Trigonometric inferences aside, we can think of Leibniz's proofs as each involving two main steps, which might be intuitively illustrated in the case of reflection,

\footnotetext{
${ }^{10}$ A more detailed discussion of Leibniz's optical derivations may be found in McDonough (forthcoming). See also, McDonough (2008).
} 
using a simplified version of Leibniz’s own diagram, by letting ACB represent a reflecting surface (straight, concave or convex), F a light source, and G a light sink (e.g. an eye). (See Figure 1)

In the first step, Leibniz constructs an equation capable of describing an infinite family of bent paths that a ray of light might take from its source to its sink. That family of paths can be depicted in the diagram by letting $C$ be any point on ACB, so that FCG will represent any of the infinitely many bent paths that the ray of light might travel from its source at F to its sink at G. In the second step, Leibniz draws on his newly developed calculus to pick out the one path that is locally determinate with respect to "ease," where ease is a measurement of distance times resistance; he identifies that path with the actual trajectory of the ray of light under idealized conditions. As Leibniz is eager to show, essentially the same two stage derivation can be applied to solve a range of cases involving refraction as well.

The “optimization approach,” or "optimization strategy,” employed in the Tentamen to derive the laws of reflection and refraction provides Leibniz with a remarkably good model of his mature understanding of contingency taken as a modality falling between what is absolutely necessary and what is absolutely arbitrary. For, on the one hand, the mathematically rigorous description of infinitely many possible but nonactual paths suggests that the behavior of light is not governed by an "absolute necessity.” On the contrary, it straightforwardly implies that a ray of light setting out from, for example, the point $\mathrm{F}$ could reach the point $\mathrm{G}$ by being reflected at any of infinitely many points $C^{\prime}$ rather than $C$. On the other hand, the identification of the actual path of a ray of light on the basis of a uniquely identifying property implies that the 
behavior of light is not governed by simple chance, that it is not "something absolutely arbitrary.” A ray of light does not randomly take any of the infinitely many possible paths from its source to its sink, but rather selects, as it were, the one path that is uniquely the "easiest."

If Leibniz's derivations in the Tentamen provide a better conceptual fit with his mature understanding of contingency in nature, they also suggest a possible solution to the historical difficulty raised above. For Leibniz's discovery that the laws of nature could be derived from axioms such as the easiest path principle might have led him to reconsider his earliest understanding of the modal status of the laws of nature in general and the equality principle in particular. That is to say, Leibniz's encounter with the optimization approach to the laws of optics might not only have provided him with his best examples of his mature understanding of contingency in nature, but also played a central role in his forming and embracing the thesis of Contingency.

Although the evaluation of such an hypothesis is made more challenging by the fact that most of Leibniz's optical writings remain unedited, and thus undated, a careful investigation of those that are currently available lends it strong support. More specifically, the optical texts which are now accessible, and can be dated in one way or another with confidence, provide good evidence for the three following claims: (1) In the early 1670's, Leibniz appears to have either been unaware of, or at least uninterested in, the sorts of non-mechanical derivations that figure so centrally in the Tentamen. (2) By 1677 at the latest - still roughly two years prior to our best dating of his change of mind with respect to the modal status of the equality principle - Leibniz hit upon, and applied to the case of reflection, what is clearly a precursor of his mature easiest path principle. 
(3) During the late 1670 's to early 1680 's, that is, during the period in which his mature understanding of contingency appears to have taken firm root, Leibniz was vigorously engaged in working out the technical and philosophical implications of the optimization approach to the laws of optics. With the overarching structure of the relevant evidence in mind, let us look in a little more detail at the textual support that can be marshaled for each of these three claims.

(1) The textual evidence in support of the first claim is provided by a family of texts, datable to the early 1670 ’s, which collectively give a good preliminary picture of Leibniz's early interest in, and approach to, the study of geometrical optics. They include a short published piece entitled Notitia Opticae Promotae ([1671] 1768, pp. 14-15), a long section from his Hypothesis Physica Nova ([1671] A VI.ii.228-231.section 22), dated letters to Spinoza ([October 1671] A II.i.252-4), Oldenburg ([April 1673] A II.i.165-169) and Marriotte ([July 1673] A.II.i.369-73), and, most helpfully for our purposes, a series of three optical studies, fortuitously edited by the Akademie editors of Leibniz’s philosophical writings and dated to 1671 (A VI.ii.309-323). ${ }^{11}$ Significantly, in none of these texts does Leibniz give any indication that he is at all interested in, or even aware of, the optimization approach to the laws of optics. That absence is especially salient in his derivations of the laws of reflection and refraction from this period, which make use only of broadly efficient, broadly mechanistic resources. So, for example, in a proof from one of the texts edited by the Akademie editors, and given the title Demonstration of the Laws of Reflection and Refraction, Leibniz proposes to derive the

\footnotetext{
${ }^{11}$ See also Gerland 14, which, although undated, most likely originates from this early period as well.
} 
two central laws of geometrical optics by considering how the impetus of a body A would be affected by its impact with a surface $b c$ (A VI.ii.309-312). (See Figure 2) Leibniz's interesting proof is not without it its own insights and innovations. To take just one example, in it he argues that reflection presupposes something like elasticity in the body being reflected - a point he imaginatively illustrates by noting that children shooting (inelastic) spit balls at flies on a window pane, will aim at a spot in front of a fly since "even if the spitball doesn't straightaway reach the place at which the fly sits, it will still be carried there and strike the fly” (A VI.ii.310). ${ }^{12}$ In spite of such novelties, however, the general approach of Leibniz's derivation follows quite closely the familiar Cartesian strategy of first decomposing the tendency of a ray of light into orthogonal tendencies, next evaluating those orthogonal tendencies at impact independently of one another, and finally recombining the relevant tendencies to determine the angle of reflection or refraction. ${ }^{13}$ In short, in spite of their ambition and inventiveness, Leibniz's optical derivations from the early 1670's suggest that, at that time, he had not yet attached any significance, or begun to apply himself, to the optimization approach to the study of laws of optics.

${ }^{12}$ Unde pueri cum factis ex charta humida globulis per calamos in muscas fenestrarum angulis insistentes collineant, sentiunt globulum oblique in vitrum emissum, etiamsi in locum cui musca insidet recta non pervenerit, per planum tamen laeve illuc deferri et ferire.

${ }^{13}$ See especially Descartes' La Dioptrique first and second discourses (1964-76, pp. 80105). 
(2) The textual evidence that Leibniz nonetheless hit upon the optimization approach to the laws of optics by the mid-1670's is provided most directly by a text, transcribed and published in 1906 by Ernst Gerland, that, although unedited, is fortunately dated in Leibniz’s own hand to 1677 (Gerland 29). ${ }^{14}$ Interestingly, the text begins with a criticism - to which Leibniz returns in his later writings - of Descartes’s attempt to explain the refraction of light by analogy to a ball's moving from a smooth

${ }^{14}$ Less direct, but still significant, support is provided by two short pieces dated and edited by the Akademie editors of Leibniz's philosophical writings. The first, tentatively dated to December 1676, reads in part, “A necessary being acts through the simplest. For among infinitely many possibilities certain ones are the simplest, but those simplest furnish the most. The reason for this is because there is no reason which determines the others. Harmony is this very thing, a certain simplicity in a multitude. [Ens necessarium agere per simplicissima. Nam ex infinitis possibilibus sunt quedam simplicissima, sed simplicissima quae plurimum praestant. Cuius rei ratio est, quia nulla est ratio quae caetera determinet. Harmonia hoc ipsum est, simplicitas quedam in multitudine.]” (A VI.iii.587-8). The second, tentatively dated to 1677-78, reads in part, "Everything in nature can be demonstrated both through final causes and through efficient causes. Nature does nothing in vain, nature acts through the shortest paths provided they are regular. Hence the shortest paths are to be sought not in refracting surfaces themselves but in tangents [Omnia in tota natura demonstrari possunt tum per causas finales, tum per causas efficientes. Natura nihil facit frustra, natura agit per vias brevissimas modo sint regulares. Hinc viae brevissimae quaerendae non in superficiebus ipsis refringentibus sed in tangentibus].” (A VI.ivB.1367; cited in Garber (forthcoming, ch. 6). 
polished surface to a surface covered by a woolen cloth. ${ }^{15}$ Concluding that "it is certain that Descartes has not rendered the true cause of refraction," Leibniz goes on to note that "Ptolemy and Heron and other ancients have used another easiest principle, namely of path, by which a ray could travel from one given point to another given point. For surely, [if] a ray reflected by the surface $\mathrm{BD}$ arrives at $\mathrm{C}$, the question is by which path, or at which point B [the ray is reflected]. ${ }^{16}$ (See Figure 3)

In the short poof that follows, Leibniz explains that the "point B should be taken such that the straight line $\mathrm{AB}+\mathrm{BC}$ conjoined is the minimum of all the other straight lines conjoined as $\mathrm{AD}+\mathrm{DC}$ (that is, having taken any other point $\mathrm{D}$ ). It is easy to show that this happens if the angles $\mathrm{ABE}$ and $\mathrm{CBD}$ are equal," that is, if the angle of incidence is equal to the angle of reflection. ${ }^{17}$ This simple derivation clearly lacks the full sophistication of Leibniz's later Tentamen proofs - it gives no indication, for example, of how one might similarly derive the law of refraction, or how the methods of the calculus

${ }^{15}$ See, Descartes (1964-1976, pp. 93-10; most specifically at p. 103); Leibniz returns to the example most significantly in ([1682]1768, 3:147-8), but also in Gerland 21, 24 (both undated). 16 “... certum est, Cartesium veram refractionis causam non reddidisse. Ptolemaeus et Heron aliique veteres alio usi sunt principio facillimo scilicet via, qua scilicet radiatio à dato puncto ad datum punctum pervenire potuit. nempe à puncto A radius à superficie $B D$ reflexus pervenit in $C$, quaeritur, qua via seu qualenam sit punctum $B$...” ${ }^{17}$... punctum $B$ debere sumi tale, ut recta $A B+B C$ aggregatum sit aliorum quorumlibet aggregatorum, $u t A D+D C$ (alio scilicet quolibet puncto D sumto) minimum. Quod facile ostenditur fieri, si anguli $A B E$ et $C B D$ sint aequales. 
might be applied to facilitate the discovery of "optimal paths." Nonetheless, it is equally clear that the central idea with respect to Contingency is already present, namely, that the actual path of a ray of light might be thought of as one of an infinite family of possible paths selected for on the basis of a uniquely determining property. We therefore have good evidence that by 1677 at the latest, roughly two years before he apparently changed his mind concerning the modal status of the equality principle, Leibniz was at least aware of, and had begun to work on, the optimization approach to the laws of optics.

(3) The textual evidence that Leibniz quickly appreciated the power and significance of that approach is provided by a fairly large family of datable texts. Perhaps the earliest of these texts is another piece that has been fortunately edited by the Akademie editors of Leibniz's philosophical writings, and has been dated by watermark to Summer 1678- Winter 1680-1 (A VI.ivB.1393-1405/LOC 237-257). In it, Leibniz first offers a broadly mechanistic derivation of the law of reflection, and then immediately afterwards offers essentially the same non-mechanistic derivation as found in the 1677 piece, drawing the conclusion, more familiar from the Tentamen, that "All the phenomena of nature can be explained solely by final causes, exactly as if there were no efficient cause; and all the phenomena of nature can be explained solely by efficient causes, as if there were no final cause” (A VI.ivB.1403/LOC 253; cf. G VII 273/L 279; A VI.ivB.1367). Five other unedited pieces, one from 1679, and four from 1681, all dated in Leibniz's own hand, show him vigorously engaged in working out the mathematical side of the optimization approach to the laws of optics (Gerland 32; Gerland 30; LH 
XXXVII.ii.66-67; LH XXXVII.ii.68-69; LH XXXVII.ii.70-73). ${ }^{18}$ These studies can be seen as culminating in the publication of one of Leibniz's most important scientific papers, his Unitary Principle of Optics, Catoptrics and Dioptrics, published in the June 1682 edition of the Acta Eruditorum. This remarkable and elegant paper contains all of the most important technical achievements more commonly associated with the much later Tentamen, including, most centrally, the presentation of a single optimization principle applicable to both cases of reflection and refraction. Collectively these texts give absolutely solid evidence that by the early 1680’s at the latest, Leibniz had not only become fully acquainted with the optimization approach to the laws of optics, but indeed had become one of its most sophisticated defenders.

Although a full and detailed account of the development of Leibniz’s optical studies must await the publication of Series VIII of the Akademie edition of his scientific, medical and technical writings, the datable texts currently available nonetheless already lend strong support to the hypothesis that Leibniz's embrace of Contingency was driven not so much by his work in dynamics, as by his studies in geometrical optics. The two sections that follow will offer further indirect evidence for such a re-reading of Leibniz's

${ }^{18}$ Electronic copies of LH XXXVII.ii.66-67; LH XXXVII.ii.68-69; LH XXXVII.ii.70-73 are now helpfully available on-line through the website of the Berlin-Brandenburgischen Akademie der Wissenschaften at http://ritter.bbaw.de/ritter. A particularly succinct example of the growing mathematical sophistication of Leibniz's optical derivations can be found in Gerland 30 (dated December 1681) which shows Leibniz using his "method of tangents” to identify a local inflection point by setting the first derivative of an equation describing the path of a ray of light equal to zero. 
intellectual development by arguing that his engagement with the optimization approach to the laws of optics in the late 1670's to early 1680's also helps to make more intelligible his concurrent adoption of the theses of Providence and Entelechies.

\section{Providence}

It has been tempting to suppose that Leibniz's embrace of Providence can be traced back to his work in dynamics through his embrace of the thesis of Contingency and his commitment to the principle of sufficient reason. That is, it has been tempting to imagine that Leibniz's discovery of the conservation of vis viva led him to the conclusion that the laws of nature are contingent, and that that conclusion, when paired with his commitment to the principle of sufficient reason, led him to the conclusion that the laws of nature must be rooted in divine providence. For if the laws of nature are contingent, the principle of sufficient reason will insist that there must be a reason for the actual laws of nature holding. But what reason could there be for the actual (contingent) laws of nature holding other than God's providential intention (cf. Bennett 2001, 267; Wilson 1976) 441-3)?

Although Leibniz might well have approved of such a line of thought, as an attempt to explain how he came to embrace the thesis of Providence, it meets with a pair of difficulties similar to those raised in the last section. Indeed, the first such difficulty is a straightforward consequence of the historical worry encountered in connection with the thesis of Contingency. For if, as has been argued, Leibniz's discoveries in physics cannot account for his embrace of Contingency then they cannot in turn account for his embrace 
of Providence as arising out of his commitment to Contingency and the principle of sufficient reason. The results of the previous section, however, provide and immediate and now obvious solution to that difficulty: for Leibniz's work in geometrical optics could have led him to see the laws of nature as contingent, and, in doing so, set the stage for a generic argument for divine providence based on the principle of sufficient reason.

The second, more interesting difficulty concerns the explanatory power of the traditional story that runs through the contingency of the laws of nature and the principle of sufficient reason. For, although the traditional story offers a generic argument for a providential creation which Leibniz certainly could have accepted, it provides no insight into how he might have arrived at the distinctive features of his mature views on divine teleology. That is say the traditional story provides no insight into why Leibniz's understanding of divine providence suddenly takes the shape that it does in the late 1670 's to early 1680 's.

It is with respect to this second difficulty that Leibniz's work in geometrical optics proves surprisingly helpful. For a closer look at the defining themes of Leibniz's mature conception of divine teleology suggests that his derivations of the laws of reflection and refraction do not merely provide a premise in an otherwise independent argument for a providential creation, but instead deeply inform his mature understanding of divine providence and its relationship to the study of the natural world as it emerges in pieces such as his Two Sects of Naturalists ([ca. 1677-1680] A VI. ivB.1384-88/AG 28184), Letter to Molanus ([ca. 1679] A II.i.499-504/AG 240-45), and The Discourse on 
Metaphysics ([1686] G IV 427-63/AG 35-68). ${ }^{19}$ Let us consider three of those themes in turn.

As a first theme, especially clear in Two Sects of Naturalists, the mature Leibniz maintains that a proper understanding of divine providence must steer a middle course between, on the one hand, the extreme of necessitarianism, which he associates with Descartes and Spinoza, and, on the other hand, a commitment to brute contingency, which he associates with Hobbes and Gassendi (A VI.ivB.1384-1386/AG 281-282; cf. A VI.ivC 1384-5; T 349/G VI 321; G VI 50). The key to this middle path, according to

${ }^{19}$ That mature view may be contrasted with Leibniz's understanding of providence in the early 1670's as witnessed especially in his twin studies the Theoria Motus Abstracti, and the Hypothesis Physica Nova (also known as the Theoria Motus Concreti) (A VI.ii.258276; A VI.ii.221-257; cf. A.VI.ii.314). In those works, Leibniz distinguishes between, on the one hand, the fundamental, "pure," or "private" laws of motion and impact as presented in the Theoria Motus Abstracti, and, on the other hand, the derived or "public" laws of nature as presented in the Theoria Motus Concreti. The former, Leibniz suggests, although necessary and knowable a priori, are nonetheless consistent with divine providence insofar as they follow from the divine will and intellect (A VI.ii.160; A VI.iii.364). The latter, Leibniz implies, are contingent, and knowable only with the aid of at least some experience; in his studies from the early 1670 's, they are taken to provide the most obvious evidence of God's providential design in nature (see, for example, A.VI.ii.255). For a helpful overview of Leibniz's early natural philosophy, and for further sources, see, for starters, Hannequin (1908, pp. 17-226). See also Beeley (1999), and Garber (forthcoming, ch. 1). 
Leibniz, lies in recognizing that in creating the actual world God selects the best from a range of possible alternatives. Leibniz thus sees defenders of necessitarianism as threatening providence by (among other things) denying that there are genuine alternatives to the actual laws of nature (see, for example AVI.iv.1385/AG 282), and defenders of brute contingency as endangering divine teleology by (among other things) implying that God acts not for the sake of the best but rather out of whim or fancy (see, for example, DM 2-3). In both his favored middle course, as well as in his very characterization of the philosophical terrain, it is not hard to see the influence of Leibniz’s “optimization” derivations. For those derivations might easily be interpreted by a pious defender of divine providence as suggesting that God selects the uniquely best laws of nature from an infinite range of alternative laws. In this way, Leibniz could see his optimization derivations as providing a powerful model not only for his mature understanding of contingency, but also for his considered views on divine providence and its relationship to the natural world (see, most strikingly, G VII 302-8/AG 149-155).

As a second theme, Leibniz suggests that explanations of natural phenomena should be approachable both in terms of God's providential reasons and in terms of broadly mechanistic efficient causes. He thus insists, for example, in the Discourse on Metaphysics that "authors who follow these different routes should not malign each other," and declares that one may "recognize and praise the skill of a worker not only by showing his designs in making the parts of his machine, but also by explaining the instruments he used in making each part” (DM 22). In the same piece he writes explicitly: 
I even find that several effects of nature can be demonstrated doubly, that is, by considering first the efficient cause and then by considering the final cause, making use, for example, of God's decree always to produce his effect by the easiest and most determinate ways, as I have shown elsewhere in accounting for the rules of catoptrics and dioptrics. (DM 21; cf A VI.ivB.1384-1388/AG 281284; A II.i501/AG 242; GM VI 243/AG 126)

This passage, of course, echoes a lesson we saw Leibniz draw in his early work Metaphysical Definitions and Reflections from 1678-1680. For, already in that piece, we found him explicitly arguing that the law of reflection may be derived both from the "way of final causes" by asking after the "best” path that a ray of light might take from its source to its sink, and mechanistically by considering how the motions of a body would be affected by its collision with a surface impeding its movement in one direction (A.VI.iv.1404-5/LC 255). In this way, Leibniz's work in optics may be seen as paving the way, again with a striking and concrete example, for another central theme of his mature understanding of divine providence, namely, that it should be explanatorily compatible with a broadly mechanistic account of bodily interactions.

Finally, as a third theme, sounded throughout his mature works, Leibniz insists over and over again that a proper defense of divine teleology should seek to show how consideration of God's ends might be positively conducive to making important discoveries in natural philosophy. Although he sometimes mentions in passing cases of well-functioning organisms in connection with this theme, his principal example in support of the utility of providential reasoning for making discoveries in the natural 
sciences simply are optimization derivations of the laws of reflection and refraction.

Thus in a characteristic passage from the Discourse on Metaphysics, he writes:

[T]he way of final causes is easier, but is nevertheless frequently of use in discovering important and useful truths, truths that would take a long time to find by the other, more physical route. Anatomy provides important examples of this; and Snell, the first formulator of the rules of refraction, would have been a long time finding them, if he had tried first to find out how light is formed. But evidently he followed the method which the ancients used for catoptrics, which is in fact that of final causes. For by looking for the easiest way to get a ray from one given point to another by reflection ... they discovered the equality of the angle of incidence and of reflection ... M. Snell, as I believe, and after him ... M. Fermat, have more ingeniously applied this to refraction. Since rays in the same media observe the same ratio of sines as that between the resistances of the media, this turns out to be the easiest, or at least the most determinate route to get from a given point in one medium to a given point in another. (DM 22/FW 75; see also SD 24/FW 164; NI 4/FW 212; TA 273/L 479)

The idea that "it is unreasonable to introduce a supreme intelligence as orderer of things and then, instead of using his wisdom, use only the properties of matter to explain the phenomena” is central to Leibniz's mature conception of divine providence (DM 19). Indeed, it is such a prevalent theme of his mature thinking that it is easy to forget what an ambitious - even dangerous - standard it sets for a pious defender of divine teleology. For, of course, it is not at all easy to show how considerations of divine ends might actually be useful for making genuine scientific discoveries, especially outside the 
domain of biology. In Leibniz's confidence that such a standard can nonetheless be met, we can see yet another way in which his optical studies might well have helped to guide and shape his mature views on divine providence.

It should be acknowledged, of course, that Leibniz also came to see his mature views on divine providence as deriving support from his work in dynamics. The connections between Leibniz's studies in physics and his mature understanding of divine teleology, however, are apt to appear more strained and $a d$ hoc. His original commitment to the necessity of the equality principle makes it an unlikely source of his mature view of providence as the key to a middle course between the Scylla of strict necessitarianism and the Charybdis of brute contingency. And, indeed, it remains somewhat ambiguous even in Leibniz's mature writings whether violations of the equality principle are really, or just apparently, possible (see, e.g. NE IV.x.437-8; SD 31). It is likewise hard to imagine Leibniz's work in physics giving rise to his thesis that "the effects of nature can be demonstrated doubly, that is by considering first the efficient cause and then by considering the final cause” (DM 21). For the only phenomena from physics that Leibniz even attempts to explain both efficiently and teleologically in the relevant way phenomena such as the shape of freely hanging chains, and the quickest non-vertical paths of falling bodies - he treats in a manner that is obviously an extension of the optimization strategy first forged in his optical studies (see, for example, G VII 304-3/L 488-9; TA 272/L 478). ${ }^{20}$ Finally, while it is easy enough to suppose that the equality principle and the conservation of vis viva are consistent with a providential design, they

\footnotetext{
${ }^{20}$ For a more detailed discussion of Leibniz's extension of his optimization strategy to such problems, see, McDonough (forthcoming).
} 
hardly seem like promising springboards for showing that considerations of divine teleology are positively useful for making scientific discoveries; while Leibniz could plausibly imagine, as he did, ${ }^{21}$ that the law of refraction would not have been discovered so soon without the aid of teleological reasoning, he could not plausibly suppose the same with respect to his favored conservation laws.

Leibniz's work in optics thus suggests a very different picture of the development of his mature views on divine providence and its relationship to the laws of nature than has traditionally been supposed. Rather than seeing his mature understanding of providence as arising from his conceptually prior commitment to the contingency of the laws of motion and the principle of sufficient reason, it suggests that his mature understanding of both Contingency and Providence have a common root in his optical studies from the late 1670's to early 1680's. This way of approaching Leibniz's mature views on divine providence and its relationship to the study of the natural world promises not merely to explain his commitment to a providential creation - something which given his piety and background, perhaps, stands in need of no explanation at all - but, more significantly, to provide insight into the central themes that most distinctively characterize his mature position. In short, Leibniz's work in optics makes his embrace of

${ }^{21}$ Although Descartes was the first person to publish the law of refraction as we know it, he was widely accused of having stolen his results from Willebrord Snell while residing in Holland. Leibniz seems to have shared in the opinion that Descartes did not discover the law of refraction and that his derivations were tailored to fit an already known result (see, TA 274/L 479-80 and DM 22/L 317-18). For discussion of the history of the dispute, see especially Korteweg (1896, pp. 489-501), and Sabra (1967). 
the thesis of Providence more intelligible, and in doing so lends support to the conjecture that his studies on the laws of reflection and refraction played a significant role in helping to shape his mature understanding of the laws of nature. The next section will suggest that those studies similarly help to make more intelligible his embrace of the thesis of Entelechies.

\section{Entelechies}

Of the three theses that characterize Leibniz's mature philosophical understanding of the laws of nature, it has perhaps been most difficult to see how his work in the natural sciences might lend support to his postulation of immaterial teleological natures ( $c f$. Russell 1997, pp. 89; Wilson 1976, pp. 433-35; Adams 1994, pp. 378). Insofar as there is a standard account linking Leibniz's work on the laws of physics to his commitment to the thesis of Entelechies, it would appear to involve two steps. ${ }^{22}$ The first step would move from the supposed difficulty of grounding the laws of nature in merely extended matter and motion to the postulation of immaterial natures or forces. The second step would move from the postulation of immaterial natures or forces to the conclusion that those natures must also be teleological. In this last main section, I'd like to suggest that Leibniz's work in geometrical optics also helps to shed light on this especially difficult

\footnotetext{
${ }^{22}$ For discussion of the relationship between Leibniz's work in physics and his postulation of entelechies, see McGuire (1976, pp. 290-326), Hartz (1984, pp. 315-332), Garber (1985, pp. 27-130), Rutherford (1992, pp. 35-49), Adams (1994, pp. 378-399), Rutherford (1995, especially pp. 237-264), and Lodge (1997, pp. 116-124).
} 
aspect of his mature understanding of the laws of nature, and, more specifically, I'd like to suggest that his optical studies provide him with at least as good of a foundation for the postulation of immaterial natures, and a stronger foundation for insisting that those natures must also be teleological.

Leibniz's argument that the laws of nature must be grounded in immaterial natures or forces is a particular instance of a more general argument form that he employs in a number of different contexts. ${ }^{23}$ That general argument might be thought of as beginning with a pair of background assumptions. One is that, for the sake of argument, matter may be understood austerely to include essentially nothing more than concrete extension and its modifications; and, as a corollary, that a purely materialistic or mechanistic metaphysics may be taken to include nothing more than matter so understood together with motion taken as relative change of position. The second assumption is that it must be possible for all natural phenomena to be intelligibly grounded in metaphysical features of the created world itself - to suppose that some phenomenon such as elasticity, hardness or gravity might be simply "superadded" to mechanistically conceived matter is, on this assumption, to have illicit recourse to perpetual miracles (see, for example, A VI.vi.66; G III 519; G VII 338-9/AG 314). The two assumptions together provide Leibniz with a general argument form that takes as input some natural phenomenon or other that is plausibly inexplicable in terms of austere matter and motion, and yields as a conclusion that that phenomenon must ultimately be grounded in immaterial natures or forces. Intuitively, the general idea is simply that we must admit the existence of some non-material natures or forces in order to adequately explain the existence of natural

${ }^{23}$ On this general argument form, see especially, Rutherford (1992, pp. 35-49). 
phenomena which cannot be accounted for in terms of merely extended matter and motion.

Leibniz suggests that the of the conservation of vis viva provides an instance of this general argument form insofar as it requires us to distinguish between a body's "quantity of motion" and its "living force.” Thus immediately after a summary presentation of his argument for the conservation law in Section 17 of the Discourse on Metaphysics, Leibniz writes in Section 18:

This consideration, the distinction between force and quantity of motion, is rather important, not only in physics and mechanics ... but also in metaphysics, in order to understand the principles better. For ... this force is something different from size, shape, and motion, and one can therefore judge that not everything conceived in body consists solely in extension and in its modifications ... Thus we are once again obliged to reestablish some beings or forms they [i.e. the "moderns"] have banished. And it becomes more and more apparent that ... the general principles of corporeal nature and of mechanics itself are more metaphysical than geometrical, and belong to some indivisible forms or natures as the causes of appearances, rather than to corporeal mass or extension. (DM 18)

Put a bit more succinctly, Leibniz's suggestion here seems to be that the conservation of vis viva requires us to distinguish between a body's quantity of motion and its living force, and that the latter cannot be intelligibly grounded in merely extended matter and motion. Thus, following the pattern of his general argument, we are supposed to be led from the conservation of vis viva to the conclusion that even the most basic laws of physics must ultimately be grounded in immaterial natures. 
Whatever one makes of Leibniz's general argument, or the specific version of it occasioned by his derivations of the conservation of vis viva, it should be conceded, I think, that the laws of optics provide him with at least as good of a foundation for postulating immaterial natures as do the laws of physics. For if it is plausible to assume that the conservation of vis viva cannot be intelligibly grounded in mere matter and motion, it is at least as plausible to suppose that the laws of reflection and refraction are similarly inexplicable without appeal to "immaterial” natures. Indeed, dialectically speaking, the laws of optics would appear to offer, if anything, a better example for Leibniz's purposes. For, on the one hand, insofar as the law of the conservation of vis viva, and even the distinction between "quantity of motion" and "living force," can be stated using only geometrical quantities akin to mass and velocity, one might feel a bit insecure in insisting that the laws of physics cannot be intelligibly grounded in mere matter and motion (cf. Sleigh 1990, pp. 117). And, on the other hand, insofar as they appeal to notions such as “ease,” "resistance,” and “determinateness,” one might reckon the laws of optics particularly good examples of natural phenomena unlikely to be intelligibly rendered in terms of austere matter and motion. The move from the laws of nature to the postulation of immaterial natures thus seems to be at least as well supported by Leibniz's work in geometrical optics as it is by his work in physics.

Even granting that the laws of the world must be rooted in immaterial natures, however, it remains a further question why those natures must also be considered teleological. Drawing on our discussion just above, one might try to see Leibniz's commitment to the postulation of specifically teleological natures as being rooted in the following line of thought: reflection on the laws of nature must lead to the postulation of 
immaterial, "metaphysical” principles; such immaterial principles, however, must be understood on the model of goal-directed minds governed by laws of perception and appetite; consequently, however, those metaphysical principles must be counted not only as immaterial but also as teleological (cf. A VI.ivC.2008-9/L 289-9; see also, G II 262/L 533). Although it must put a lot of weight on a pair of fairly thin associations - on the one hand, between immateriality and mentality, and on the one hand, between mentality and final causality - this line of argument might well represent the most promising way for Leibniz to link his work in physics to his commitment to the thesis of Entelechies.

Here as well, we might begin by noting that, insofar as Leibniz's argument for teleological natures is made to rest ultimately on those laws being inexplicable in terms of austere matter and motion, his work on the laws of optics would seem to support it at least as well as his work on the laws of physics. More significantly, however, Leibniz's work in geometrical optics also suggests a much more direct and intuitive argument for the conclusion that if there are immaterial forces grounding the laws of nature, they - or at least the ones grounding the laws of optics - must, in some sense, be teleological. For Leibniz sees the laws of optics themselves as, in an important sense, teleological: they allow us to explain the behavior of rays of light by appealing to the expected outcomes of their behavior. Using Leibniz's easiest path principle, we are thus able to say, for example, that a ray of light passed through point B rather than $\mathrm{B}^{\prime}$ in order to get to $\mathrm{C}$ by the easiest path in much the same way that we are able to say that the flower bloomed in order to facilitate pollination, or the bird flew south in order to avoid the cold weather. Whether one agrees or not that such explanations commit one to teleology within the 
order of nature, it is not difficult to see why Leibniz thinks that they do. ${ }^{24}$ Granting that conclusion, however, he has a rather straightforward reason for thinking that at least some of the laws of the natural world are grounded in natures which are not just immaterial but also teleological, a reason, or line of reasoning, that, to its credit, does not rely on any associations between immateriality, mentality, and final causality. For if it is granted both that the laws of optics may be understood teleologically and that they must be grounded in immaterial natures, it is but a small step indeed to the conclusion that those immaterial natures may also be understood to be in some sense teleological. In this way, the laws of reflection and refraction provide Leibniz not just with another instance of phenomena that are plausibly inexplicable in terms of austere matter and motion, but also the foundations for a surprisingly straightforward defense of immanent teleology.

In closing this section, it may be worth noting that this way of approaching Leibniz's embrace of Entelechies may also help to shed light on the structure of a crucial stretch of the Discourse on Metaphysics. In Sections 17 and 18 of that work, Leibniz first presents a summary derivation of the conservation of vis viva, and then, as we have seen, draws the conclusion that the laws of physics cannot grounded be "solely in extension and in its modifications ... [ [so that] we are once again obliged to reestablish some beings or forms they have banished.” Next, in Sections 19 through 22, he offers an extended defense of teleology that, again as we have seen, culminates in the example of the laws of optics, with Leibniz declaring "Snell, who first discovered the rules of refraction ... followed the method which the ancients used for catoptrics, which is in fact that of final

${ }^{24}$ For a limited defense of Leibniz's characterization of principles such as the easiest path principle as teleological, see McDonough (forthcoming). 
causes." Finally, in Section 23, Leibniz suggests that having "found it appropriate to insist a bit on these considerations of final causes, incorporeal natures, and an intelligent cause with respect to bodies ... It is now appropriate to return from bodies to immaterial natures, in particular to minds, and to say something of the means God uses to enlighten them and act on them.” Given the traditional understanding of Leibniz's embrace of Entelechies this structure must appear rather puzzling since according to it we should expect Leibniz's defense of immanent teleology to follow, rather than precede, his discussion of mental natures. The actual structure of this stretch of the Discourse, however, makes perfectly good sense if we see Leibniz's work on the laws of optics as providing him with an argument for specifically teleological natures that does not presuppose the postulation of natures that are essentially mental.

\section{Conclusion}

Leibniz was never shy about trumpeting his discoveries in both the domains of optics and physics, and there should be no doubt that he came to see his work in both fields as supporting the central theses of what we would characterize as his mature philosophy of nature or science. Nonetheless, in attempting to understand the dramatic shift in Leibniz's thinking about the natural world during the crucial period following his stay in Paris, recent commentators have typically focused on his work on the laws of dynamics at the expense of his work on the laws of optics. It has been the aim of this paper to show, most specifically, how Leibniz's embrace of three of the most important themes of his mature understanding of the laws of nature may be rendered more intelligible when 
viewed against the backdrop of his derivations of the laws of reflection and refraction, and, more generally, to suggest that closer attention to his important work in geometrical optics may point the way towards a more sympathetic understanding of his mature natural philosophy. ${ }^{25}$

${ }^{25}$ I would like to thank Daniel Garber, Sam Levey, and Daniel Sutherland for their helpful suggestions on earlier drafts of this paper. I am also grateful for assistance with texts provided by Drs. Eberhard Knobloch, Sebastian W. Stork, and Hartmut Hecht at the Berlin-Brandenburgische Akademie der Wissenschaften, as well as for funding for research in Germany provided by a Kristeller-Popkin Travel Fellowship sponsored by the Journal of the History of Philosophy. 


\section{References}

Adams, Robert. 1994. Leibniz: Determinist, Theist, Idealist. Oxford: Oxford University Press.

Beeley, Philip. 1999. “Mathematics and Nature in Leibniz's Early Philosophy.” Pp. 123145 in The Young Leibniz and his Philosophy (1646-76). Edited by Stuart Brown. Dordrecht: Kluwer.

Bennett, Jonathan. 2001. Learning from Six Philosophers, Volume 1. Oxford: Oxford University Press.

Bos, J. M. 1978. “The Influence of Huygens on the Formation of Leibniz’s Ideas.” Studia Leibnitiana Supplementa 17: 59-68.

Descartes, Rene. 1964-1976. Oeuvres de Descartes, nouvelle presentation. Edited by C. Adam and P. Tannery. Paris: Vrin.

Gale, George. 1973. “Leibniz’ Dynamical Metaphysics and the Origins of the Vis Viva Controversy.” Systematics 11: 184-207. 
Garber, Daniel. 1985. “Leibniz and the Foundations of Physics: The Middle Years.” Pp. 27-130 in The Natural Philosophy of Leibniz. Edited by K. Okruhlik and J. R. Brown. Dordrecht: Reidel. . 1995. “Leibniz: Physics and Philosophy.” Pp. 309-315 in The Cambridge Companion to Leibniz. Edited by Nicholas Jolley. New York: Cambridge University Press. . Forthcoming. Enchanting the World: Leibniz on Body, Substance and Monad.

Gueroult, Martial. 1967. Leibniz: Dynamique et Métaphysique. Paris: AubierMontaigne.

Hannequin, Arthur. 1908. “La première philosophie de Leibniz.” Pp. 17-226 in Études d'histoire des sciences et d'histoire de la philosophie. Paris: F. Alcan.

Hartz, Glenn. 1984. "Launching a Materialist Ontology: The Leibnizian Way.” History of Philosophy Quarterly 1:3: 315-332.

Iltis, Carolyn. 1974. “Leibniz’s Concept of Force: Physics and Metaphysics.” Pp. 143-9 in Studia Leibnitiana Supplementa, Vol. XIII. Band II: Weisbaden: Franz Steiner Verlag. . 1979. "Leibniz and the Vis Viva Controversy.” Isis 62: 21-35.

Korteweg, D. J. 1896. “Descartes et les manuscrits de Snellius d'après quelques documents nouveaux.” Revue de métaphysique et de morale IV: 489-501. 
Laudan, L. L. 1968. “A Postmortem on the Vis Viva Controversy.” Isis 59: 296-300.

Leibniz, Gottfried Willhelm. 1675. “De Arcanis Motus et Mechanica ad puram Geometriam reducenda.” Reproduced in Heinze-Jürgen Hess, “Die Unveröffentlichen Naturwissenschaftlichen und Technischen Arbiten von G. W. Leibniz Aus Der Zeit Seines Parisaufenthaltes. Eine Kurzcharakteristik.” Studia Leibnitiana Supplementa, Volume XVII, Tome I, 202-210 .1686. “Discourse on Metaphysics.” Reprinted in Die Philosophischen Schriften von Gottfried Wilhelm Leibniz, 7 volumes. Edited C. I. Gerhardt. Berlin: Weidmannsche Buchhandlung. 1875-1890. 4: 427-63. . 1695. “A Specimen of Dynamics.” Reprinted in Mathematische Schriften, 7

volumes. Edited by C. I. Gerhardt. Berlin: A. Asher; Halle: H. W. Schmidt. 6: 235-54. . 1698. “On Nature Itself.” Reprinted Die Philosophischen Schriften von Gottfried Wilhelm Leibniz, 7 volumes. Edited by C. I. Gerhardt. Berlin: Weidmannsche Buchhandlung. 1875-1890. 4: 504-16 . 1768. Opera Omnia. Edited by L. Dutens. Geneva: Fratres De Tournes. . 1849-. Mathematische Schriften, 7 volumes. Edited by C. I. Gerhardt. Berlin: A.

Asher; Halle: H. W. Schmidt. .1875-. Die Philosophischen Schriften von Gottfried Wilhelm Leibniz, 7 volumes.

Edited by C. I. Gerhardt. Berlin: Weidmannsche Buchhandlung. . 1889. Die Leibniz-Handschriften der Königlichen öffentlichen Bibliothek zu

Hannover. Eduard Bodemann. Hannover. Reprinted 1966. Hildesheim: Georg Olms. 
. 1906. Leibnizens Nachgelassene Schriften Physikalischen, Mechanischen und

Technischen Inhalts. Edited by Ernst Gerland. Leipzig: B. G. Teubner. Reprinted 2006. Ann Arbor, Michigan: University of Michigan University Library.

. 1923-. Sämtliche Schriften und Briefe. Darmstadt and Berlin: Berlin Academy. . 1969. Philosophical Papers and Letters, $2^{\text {nd }}$ Edition. Edited and translated by L.

E. Loemker. Dordrecht: Reidel.

. 1985. Theodicy. Reprinted in Die Philosophischen Schriften von Gottfried

Wilhelm Leibniz, 7 volumes. Edited by C. I. Gerhardt. Berlin: Weidmannsche

Buchhandlung. 1875-1890. Translated by E.M. Huggard. Illinois: Open Court Publishing Company.

.1988. Philosophical Texts. Edited and translated by R. Franks and R. Woolhouse.

New York: Oxford University Press.

.1989. Philosophical Essays. Edited and translated by R. Ariew and D. Garber.

Indianapolis: Hackett.

. 1996. New Essays on Human Understanding. Reprinted in Sämtliche Schriften

und Briefe. Darmstadt and Berlin: Berlin Academy A.VI.6. Translated by P. Remnant. and J. Bennett. Cambridge: Cambridge University Press. 2001. The Labyrinth of the Continuum, Writings on the Continuum Problem, 1672-1686. Edited and translated by Richard Arthur. New Haven: Yale University Press.

Lodge, Paul. 1997. "Force and the Nature of Body in Discourse on Metaphysics, §§1718,” Leibniz Society Review 17: 116-124. 
McDonough, Jeffrey K. 2008. “Leibniz’s Two Realms Revisited,” Nôus 42:4: 673-696. . Forthcoming. "Leibniz on Natural Teleology and the Laws of Optics.” Philosophy and Phenomenological Research.

McGuire, J. E. 1976. “'Labyrinthus Continui': Leibniz on Substance, Activity, and Matter.” Pp. 290-326 in Motion and Time, Space and Matter: Interrelations in the History of Philosophy and Science. Edited by Peter Machamer and Robert Turnbull. Ohio: Ohio State University Press.

Okruhlik, Kathleen. 1995. "The Status of Scientific Laws in the Leibnizian System.” Pp. 183-206 in The Natural Philosophy of Leibniz. Edited by Kathleen Okruhlik and J. R. Brown. Dordrecht: Reidel.

Posner, Hans. 1984. “Apriorismus der Prinzipien und Kontingenz der Naturgesetzen. Das Leibniz-Paradigma der Naturwissenshaft.” Studia Leibnitiana Sonderheft 13: 164791.

Russell, Bertrand. [1937] 1997. A Critical Exposition of the Philosophy of Leibniz, Second Edition. London: Routledge.

Rutherford, Donald. 1992. “Leibniz’s Principle of Intelligibility.” History of Philosophy Quarterly, 9:1: 35-49. 

1995. Leibniz and the Rational Order of Nature. Cambridge: Cambridge

University Press.

Sabra, A. I. 1967. Theories of Light from Descartes to Newton. London: Olbourne.

Sleigh, Robert. 1990. Leibniz \& Arnauld: A Commentary on Their Correspondence. New Haven: Yale University Press.

Smith, George E. "The vis viva dispute: A controversy at the dawn of dynamics." Pp. 3136. Physics Today, October 2006.

Westfall, Richard S. 1971. Force in Newton's Physics: The Science of Dynamics in the Seventeenth Century. New York: Elsevier Publishing Company. . 1984. “The Problem of Force: Huygens, Newton, Leibniz,” Studia Leibnitiana Soderheft 13: 71-84.

Wilson, Margaret. 1976. “Leibniz’s Dynamics and Contingency in Nature.” Pp. 264-89 in Motion and Time, Space and Matter. Edited by R. Turnbull and P. Machamer. Columbus: Ohio State University Press. Reprinted in Margaret Wilson. 1999. Ideas and Mechanism: Essays on Early Modern Philosophy. Pp. 421-441. Princeton: Princeton University Press. 


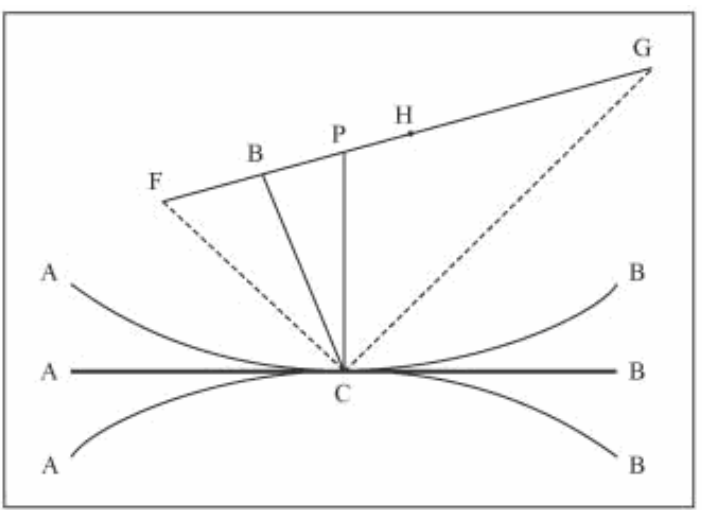

Figure 1 


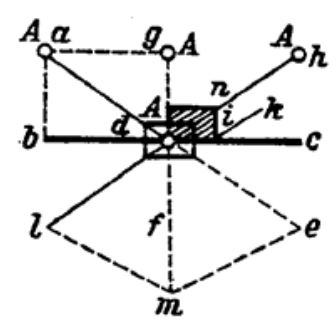

Figure 2 


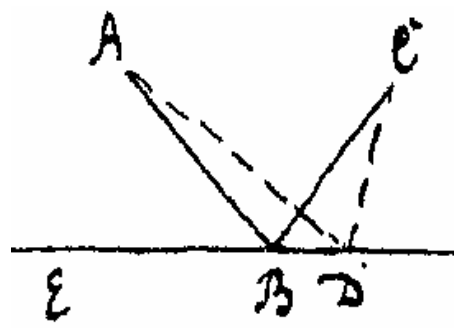

Figure 3 